\title{
Application of Linear Programming Technique in the Determination of Optimum Production Capacity
}

\author{
A.E. Anieting, V. O. Ezugwu and S. Ologun \\ Department of Mathematics and Statistics University of Uyo, Nigeria
}

\begin{abstract}
In this paper, we were concerned with applying linear programming technique to determine optimum production of Usmer Water Company, Uyo. TORA Software was used in the analysis of the data using $M-$ method. The result showed the values of the decision variables, $x_{1}, x_{2}, x_{3}, x_{4}$ and $x_{5}$ to be 95, 0, 5.9, 10 and 17 respectively. Sensitivity Analysis of the problem was also discussed.
\end{abstract}

Keywords: Linear Programming, Optimum Production, Model, Maximization.

\section{Introduction:}

Optimization has become a common phenomenon in almost all organizations and establishments. In developed, countries managerial decisions are mostly based on the use of optimization techniques. In a profit seeking organizations, the Board of Directors has many things to tackle which may include: The problem of other competitors in the same business, availability of funds for new capital projects, reduction of operational cost, high level of output and ultimately maximization of profit as explained by Nonso (2005).

In an attempt to address these problems there are two techniques of operation that may be applied. They include: The quantitative technique and the qualitative technique. Quantitative technique which is preferred involves modeling of a 'real form' problem into a mathematical form which can be solved to arrive at a Solution that would aid the decision makers. Linear programming (LP) technique is such a Quantitative technique: It is a widely used Mathematical modeling technique concerned with the efficient allocation of limited resources to known activities with the objective of meeting the desired goal (Taha, 1977).

In 1947, during World War II, George B. Dantzing while working with the US Air force, developed LP model primarily for solving military logistics problems. But now, it is extensively being used in all functional areas of management, airlines, agriculture, military operations, oil refining, education, energy planning, health care system etc.

Frizzone, et al (1997) used linear programming model to optimize the water resource used in irrigation, and obtained an optimal way of water resource usage. Though, considering the numerous constraints, he had to develop a separate mathematical model to achieve his goal. He noted that the mathematical programming quantifies an optimal way of combing scarce resources to satisfy the proposed goals; that is to analyze the cases where the available resources must be combined in a way to maximize the profit or minimize cost.

Nonso (2005) in his work on Application of Linear programming for Managerial Decision found out how an organization can have effective control over materials for input during production. He observed that units produced must be assumed as what is sold in order to achieve the company's goal.

Fagoyinbo, I. S. and Ajibode, I, A. (2010) worked on the Application of Linear programming Techniques in the Effective use of resources for staff training. The method employed gave an integer optimum solution to all the models formulated. The Data used did not yield a feasible solution but when the model reformed gave an optimum solution.

B. I. Ezema and U. Amakom (2012) worked on optimizing profit with the linear programming model: A focus on Golden plastic Industry limited. Enugu. 2012. The result they had showed that only 2 sizes of the total 8 'PVC' pipes should be produced.

I. U.Khan, N. H. Bajuri and I. A. Jadoon (2011) in their work, optimal production levels for the different products manufactured at ICL, a multinational Company in Pakistan had a result that showed that the amount was raised by changing production patterns within the first, second, third and fourth digit respectively. The intention of this paper is therefore to determine the optimum production capacity of Usmer water company, Uyo, Nigeria.

\section{Methodology}

Linear Programming is a mathematical technique for generating and selecting the optimal or the best solution for a given objective function. It may be defined as a method of optimizing (i.e maximizing or minimizing) a linear function for a number of constraints stated in the form of linear equations.

The general linear programming problem (or model) with $n$ decision variables and $m$ constraints can be stated in the following form. 
(Max or min) $z=c_{1} x+c_{2} x_{2}+\ldots+c_{n} x_{n}$

Subject to Linear Constraints of the form

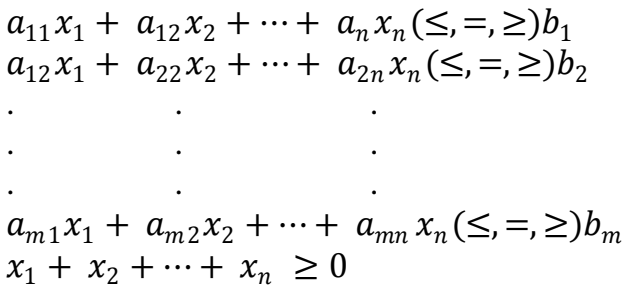

The above formulation can also be expressed in a compact form. Using summation sign (Max or Min) $Z=$ $\sum_{j=1}^{n} c_{j} x_{j} \ldots \ldots$. (Objective function) Subject to the linear constraints $\sum_{j=1}^{n} a_{i j} x_{j}(\leq,=\geq) b_{i}, i=1,2, \ldots . m \ldots$ (Constraints)

and $x_{j} \geq 0, j=1,2, \ldots, n$

.(Non-negativity conditions). Specifically the linear programming

model for this paper is given by

Maximize $Z=c_{1} x_{1}+c_{2} x_{2}+c_{3} x_{3}+c_{4} x_{4}+c_{5} x_{5}$ (objective function)

Subject to

$a_{11} x_{1}+a_{12} x_{2}+a_{13} x_{3}+a_{14} x_{4}+a_{15} x_{5} \leq b_{1}$ (Cost constraint)

$a_{21} x_{1}+a_{22} x_{2}+a_{23} x_{3}+a_{24} x_{4}+a_{25} x_{5} \leq b_{2}$ (Production time Constraint)

$a_{i 1} x_{c}+a_{i 2} x_{i}+a_{i 3} x_{i}+a_{i 4} x_{i}+a_{i 5} x_{i} \leq b_{i}$ (Demand or sales constraint)

$x_{1}, x_{2}, x_{3}, x_{4}, x_{5} \geq 0$.

And the assumptions for this model are

\section{Model Assumptions}

a. The production quantity is the same as the sales. As it is unrealistic to produce what is not sold.

b. There is a linear relationship among the variables used in the model

Where $x_{1}=$ Sachet Bag of water

$$
\begin{aligned}
& x_{2}=50 \mathrm{cl} \text { (carton) of water } \\
& x_{3}=75 \mathrm{cl} \text { (carton) of water } \\
& x_{4}=1.5 \text { liters (carton) of water } \\
& x_{5}=10 \text { liters Refillable of water }
\end{aligned}
$$

And $c_{k}=$ Product Price - Product Cost

$k=1,2, \ldots, 5\left(\right.$ ie $\left.c_{1}=45, c_{2}=200, c_{3}=250, c_{4}=450, c_{5}=500\right)$

\section{Data Presentation}

The data for this study are in the table 1 below which were extracted from the sales record of Usmer water company (Uyo, Nigeria) in September, 2012.

Table 1

\begin{tabular}{|c|l|c|c|c|c|l|}
\hline $\begin{array}{l}\text { S/ } \\
\mathbf{n}\end{array}$ & $\begin{array}{l}\text { Product } \\
\text { Package }\end{array}$ & $\begin{array}{l}\text { Production } \\
\text { Time(mins) }\end{array}$ & $\begin{array}{l}\text { Production Cost } \\
(\mathbf{N})\end{array}$ & $\begin{array}{l}\text { Selling Price } \\
(\mathbf{N})\end{array}$ & $\begin{array}{l}\text { Lowest } \\
\text { Purchase } \\
\text { (Daily) }\end{array}$ & $\begin{array}{l}\text { Highes } \\
\text { Purchase } \\
\text { (Daily) }\end{array}$ \\
\hline 1 & Sachet Bag & 3.3 & 35 & 80 & 95 & 883 bags \\
\hline 2 & $50 \mathrm{cl}$ (carton) & 6.8 & 200 & 400 & 0 & 10 cartons \\
\hline 3 & $75 \mathrm{cl}$ (carton) & 7.2 & 250 & 500 & 0 & 32 cartons \\
\hline 4 & $\begin{array}{l}1.5 \text { liters } \\
\text { (carton) }\end{array}$ & 9.0 & 400 & 950 & 0 & 10 cartons \\
\hline 5 & $\begin{array}{l}10 \text { liters } \\
\text { Refillable }\end{array}$ & 2.0 & 0 & 500 & 1 drum & 178 drum \\
\hline
\end{tabular}

Working Hours $8 \mathrm{am}$ - 4Pm daily ie 480mins ( $8 \mathrm{hrs}$ )

The Formulated Model is given as

Maximize $45 x_{1}+200 x_{2}+250 x_{3}+450 x_{4}+500 x_{5}$

Subject to.

$35 x_{1}+200 x_{2}+250 x_{3}+400 x_{4}+0 x_{5} \leq 20000$

$3.3 x_{1}+6.8 x_{2}+7.2 x_{3}+9.0 x_{4}+2 x_{5} \leq 480$

$x_{1} \quad \leq 883$ 


\begin{tabular}{ccccc}
\multicolumn{1}{c}{$x_{2}$} & & & $\leq 10$ & \\
& $x_{3}$ & & & $\leq 32$ \\
& & $x_{4}$ & & $\leq 10$ \\
& & & $x_{5}$ & $\leq 17$ \\
& & & & $\geq 95$ \\
$x_{1}$ & & & $x_{5}$ & $\geq 1$ \\
$x_{1}, x_{2}, x_{3}, x_{4}, x_{5} \geq 0$ & & & &
\end{tabular}

\section{Data Analysis and Results}

The data were analyzed using computer software - TORA and the solution is given thus $x_{1}=$ $45, x_{2}=0, x_{3}=5.9, x_{4}=10, x_{5}=17$.

Therefore the final solution is

Maximize $Z=45(95)+200(0)+250(5.9)+450(10)+500(17)=18,750$

The summary of the result is given in Table 2 below

Table 2

\begin{tabular}{|c|l|c|c|c|}
\hline S/n & Variable & Value & Obj coeff & Obj val.contribution \\
\hline 1 & Sachet & 95 & 45 & 4275 \\
\hline 2 & $50 \mathrm{cl}$ & 0 & 200 & 0 \\
\hline 3 & $75 \mathrm{cl}$ & 5.9 & 250 & 1475 \\
\hline 4 & 1.5 liters & 10 & 450 & 450 \\
\hline 5 & 10 liters & 17 & 500 & 8500 \\
\hline
\end{tabular}

\begin{tabular}{|c|c|c|}
\hline Constraint & RHS & Black -/Surplant \\
\hline$<$ & 20000 & $9199.3 /-$ \\
\hline$<$ & 480 & 0 \\
\hline$<$ & 883 & $788-$ \\
\hline$<$ & 10 & $10-$ \\
\hline$<$ & 32 & $26.10-$ \\
\hline$<$ & 10 & 0 \\
\hline$<$ & 17 & 0 \\
\hline$>$ & 95 & 0 \\
\hline$>$ & 1 & 0 \\
\hline
\end{tabular}

\section{Discussion}

The results or solutions in table 2 require that the company shows produce daily,

- 95 Bags of Sachet water

- 0 Cartons of 50cl water

- 65 Cartons of $75 \mathrm{cl}$ water

- 10 Cartons of 1.5 liters water

- 17 drums of refillable 10liters

Note that a bag contains 20 Sachets while a carton contains 12 bottles. Also it is noticed that if the company embarks on this plan the following results would follow|:

a. 9199.31 of 20,000 (Maximum Production Cost) shall be unused cost.

b. Total working time of 480 minutes shall be fully exhausted /utilized.

c. A deficit production of 788 bags of sachet water may occur if demand increased to 883 bags and would require

d. 26 bottles of $75 \mathrm{cl}$ bottles shall be deficit production.

e. Considering the sales records the company should be able to meet up with demand for 1.5 liters bottled and 10 liters refillable drum of water

\section{Sensitivity Analysis}

This was performed still using Tora software and the result is as follows in Table 3. 
Table 3

\begin{tabular}{|c|l|c|l|l|c|}
\hline S/n & Variable & $\begin{array}{l}\text { Current Obj } \\
\text { coefficient }\end{array}$ & $\begin{array}{l}\text { Min Obj } \\
\text { Coefficient }\end{array}$ & $\begin{array}{l}\text { Max obj } \\
\text { Coefficient }\end{array}$ & D Price \\
\hline 1 & Sachet bag & 45 & -infinity & 114.58 & 0 \\
\hline 2 & $50 \mathrm{cl}$ & 200 & - infinity & 236.11 & 36.11 \\
\hline 3 & $75 \mathrm{cl}$ & 250 & 211.76 & 360 & 0 \\
\hline 4 & 1.5 liters & 450 & 312.50 & infinity & 0 \\
\hline 5 & 10 refillable & 500 & 69.44 & infinity & 0 \\
\hline
\end{tabular}

\begin{tabular}{|c|c|c|c|l|c|}
\hline S/n & Constraints & Current & Min RHs & Max RHs & D Price \\
\hline 1 & $<$ & 20,000 & 10800.69 & Infinity & 0 \\
\hline 2 & $<$ & 480 & 437.50 & 667.9 & 34.72 \\
\hline 3 & $<$ & 883 & 95 & Infinity & 0 \\
\hline 4 & $<$ & 10 & 0 & Infinity & 0 \\
\hline 5 & $<$ & 32 & 5.9 & Infinity & 0 \\
\hline 6 & $<$ & 10 & 0 & 14.72 & 137.5 \\
\hline 7 & $<$ & 17 & 0 & 38.25 & 430.56 \\
\hline 8 & $>$ & 95 & 38.06 & 107.88 & 69.58 \\
\hline 9 & $>$ & 1 & 0 & 5.6 & 0 \\
\hline
\end{tabular}

Conclusion: linear programming method has proven, given the raw data the only way the company production problem can be addressed.

\section{Reference}

[1]. Ezema, B.I. and Amakon . U. (2012) Optimizing profit with the linear programming Model: A case on Boldem plastic industry limited enugu Inter disciplinary Journal of Research in Business Vol 4 Is 2 pp 37-49

[2]. Fagoyinbo, I. S. and Ajibode, I. A (2010) Application of linear programming move Techinque in one effective use of resources for staff training

[3]. Frizzone J. et al (1997) linear programming model to optimize the water resource use in irrigation

i. Inter disciplinary Journal of Research in Business Vol 1 Pg 136-148

[4]. Khan, I. U., Bajuri, N.H. and Jadom I. A(2011) Optimal production levels for the different products manufactures at ICL a multinational Company in Pakistan

[5]. Nonso, A (2008) Application of linear programming for Managerial Decision (unpublished)

[6]. Sharma J. K. (1997) Operation Research; Theory and Application $4^{\text {th }}$ Edition Macmillan Publishers india, Ltd. Pg.31-32.

[7]. Taha H. (1997) Operations Research; An introduction, Second Edition Macmillan Publishing Co. inc New York Pg 42-45. 